\title{
INTEGRATED APPROACH TOWARDS SUSTAINABLE DEVELOPMENT
}

\section{Shrivastava, P. and O'Mahony, M.}

Published as: Shrivastava, P., O'Mahony, M., Integrated approach towards sustainable development, World Review of Intermodal Transport Research, 3, (1/2), 2010, p26 - 45

Abstract: Public transport systems, both rail and road, have over previous years developed relatively independent of each other and in competition with the private car. In recent years the changes in demand for public transport due to increase in car ownership, changes in land use and wider economic forces have highlighted the importance of integrating existing networks as an alternative to mass development of new transport systems. At the same time, citizens are becoming more demanding: they expect the shortest possible journey, a high-service frequency, clear and reliable information, a comfortable and peaceful journey, a clean and attractive environment and, of course, a high level of safety. This multi-faceted challenge can only be addressed by adopting an integrated approach to mobility issues with the support of all protagonists: political decision-makers, organizing authorities, operators, manufacturers, providers of funds, etc. This approach must be based on twin foundations: on the one hand, the coordination of urban policies with journey policies, and, on the other hand, modal integration between transport networks. The integration of different modes including Non Motorised Transport (NMT) with public transport services is essential for sustainable development and is a real challenge for transport planners. In view of the above the overall concepts of system integration, issues related to integration of NMT services with public transport modes, more effective operations of Demand Responsive Transport (DRT) over conventional bus services in the present scenario, improvement of network characteristics due to integration of modes etc have been discussed in this paper. Various policies, issues, challenges and problems to be faced for integrated urban mass transportation system planning towards sustainable development are presented in this paper.

\section{Introduction}

By 2015, there will be over 500 cities with populations in excess of one million and 50 metropolitan areas with over 10 million inhabitants (Mezghami, 2003). Demographic growth in cities has been accompanied by significant expansion on the part of built up areas. The consequences of urban sprawl are well known like difficulty in serving social ties, car dependency, longer journeys, increase in 
transport expenditure, traffic congestion and environmental degradation. Table 1 shows the relative cost of public transport versus private transport. The direct financial costs of journeys made by private modes of transport take up 6.7 percent of GDP in Western Europe, compared with only 1.6 percent of GDP for public modes of transport. Public transport is not only relatively economical but also it has following advantages (Mezghami, 2003): 1) it takes less space on roads; 2) in energy terms, public transport consumes 3 to 5 times less per passenger carried; 3) public transport is 3 to 10 times less polluted than car; 4) it leads to higher road safety; and 5) it is easily affordable by each section of society.

Table 1 Comparison of costs between Public and Private Transport

$\begin{array}{lccc}\text { Region } & \begin{array}{c}\text { Cost using private } \\ \text { modes ( percent of } \\ \text { GDP) }\end{array} & \begin{array}{c}\text { Cost using public } \\ \text { modes ( percent of } \\ \text { GDP) }\end{array} & \begin{array}{c}\text { Journey cost } \\ \text { ( percent of } \\ \text { GDP ) }\end{array} \\ \text { US \& Canada } & 11.8 & 0.7 & 12.5 \\ \text { Oceania } & 12.3 & 1.1 & 13.4 \\ \text { Western Europe } & 6.7 & 1.6 & 8.3 \\ \text { Central \& Eastern Europe } & 12.4 & 2.4 & 14.8 \\ \text { Asia (affluent cities) } & 3.8 & 1.6 & 5.4 \\ \text { Asia (other cities) } & 11.4 & 2.2 & 13.6 \\ \text { Middle East } & 7.7 & 1.5 & 9.2 \\ \text { Africa } & 17.3 & 4.4 & 21.7 \\ \text { Latin America } & 11.7 & 2.6 & 14.3\end{array}$

Source: UITP Millennium Cities Database for Sustainable Transport, 2003

During 1980 and 1998, the average distance travelled by bus per person in the UK declined by more than a fifth. During the same period, most EU countries experienced growth in demand for bus travel. Austria and Sweden were up by more than 20 percent, Denmark by more than 40 percent and Italy by more than one half. Over the same period, car travel per person in the UK rose by 51 percent. However the average distance travelled by bus per person in the UK declined by more than a fifth (Commission for Integrated Transport, 2001).

In developing countries like India due to heavy growth in population and increase in industrial and commercial activities especially in metropolitan cities there is emergence of new demands for transport facilities. This has led to very heavy demands on the existing transportation infrastructure. 
The growth of these industrial and commercial activities has enlarged the city boundaries. Due to such expansion, the trip lengths have increased enormously. Such large-scale long trips by personalised and intermediate public transport modes prove to be uneconomical, create congestion, excessive energy consumption, extended journey times and environmental pollution (Government of India, 1987). At the same time the public expectancy has also increased thus it is no longer enough to transport passengers - they must also be satisfied customers, whose loyalty has to be earned.

The multi-faceted challenges can only be addressed by adopting an integrated approach to mobility issues. Efficiently integrated mass transportation systems, lead to overall system integration with special emphasis on Integrated Public Transportation System (IPTS). The long-range goal of system integration is to incorporate all components of urban transportation into a single co-ordinated planning and operations program that can make the most efficient use of available transportation resources to ensure urban mobility within a wide range of modal options to better serve the users. A project called INTRAMUROS was funded by European commission to enhance urban mobility by integration during January 1997 and March 1998. The project was led by the Spanish company ETRA and six countries Spain, Italy, Greece, France, UK and Finland participated in this. Under this project a methodology was developed and validated to assess the integration of various urban transport actors - public transport operators, traffic authorities etc (European Commission, 1999).

\section{$2 \quad$ Integrated mass transportation system}

In order to offer a genuine alternative to the car, public transport must be able to offer the most comprehensive and flexible service possible. It is vital that integrated networks be developed between the various modes and various operators. In the eyes of users, the network must appear unique and offer complete solutions. Regardless of the number of operators or modes, the network's physical and operational continuity should be guaranteed (White, 2002). There must be a single ticketing system and a single source of information about timetables and services. Recent developments in terms of information and communication technologies should favour the integration of fares and information.

Identification of the main transit facility which is best suited for the urban area under consideration is a must for an integrated system. Other transportation facilities should compliment the 
main transit facility. In Figure 1 an overall integrated system is shown (Shrivastava and Dhingra 2001). In the figure it is indicated that for an efficient overall integrated transportation system the main transit facility should offer long distance journeys. Other transport services, like intermediate public transport, private transport, public buses and Non Motorised Transport (NMT) should complement the main transit facility. Facilities should be provided for NMT commuters to avail the opportunity of transferring to main transit facility and feeder services. Similarly private and intermediate transport services should also compliment both the main transit facility as well as feeder public transport services. The commuters will be able to select appropriate mode as per their choice, requirement and trip lengths and will be able to transfer from one mode to other if needed. A main transit facility can be in terms of suburban railway, Mass Rapid Transit (MRT), Light Rail Transit (LRT) etc. The feeder public transport services can be in terms of public buses. Hourly passenger carrying capacities of various public transport systems are as shown in Table 2 (Patankar, 1999).

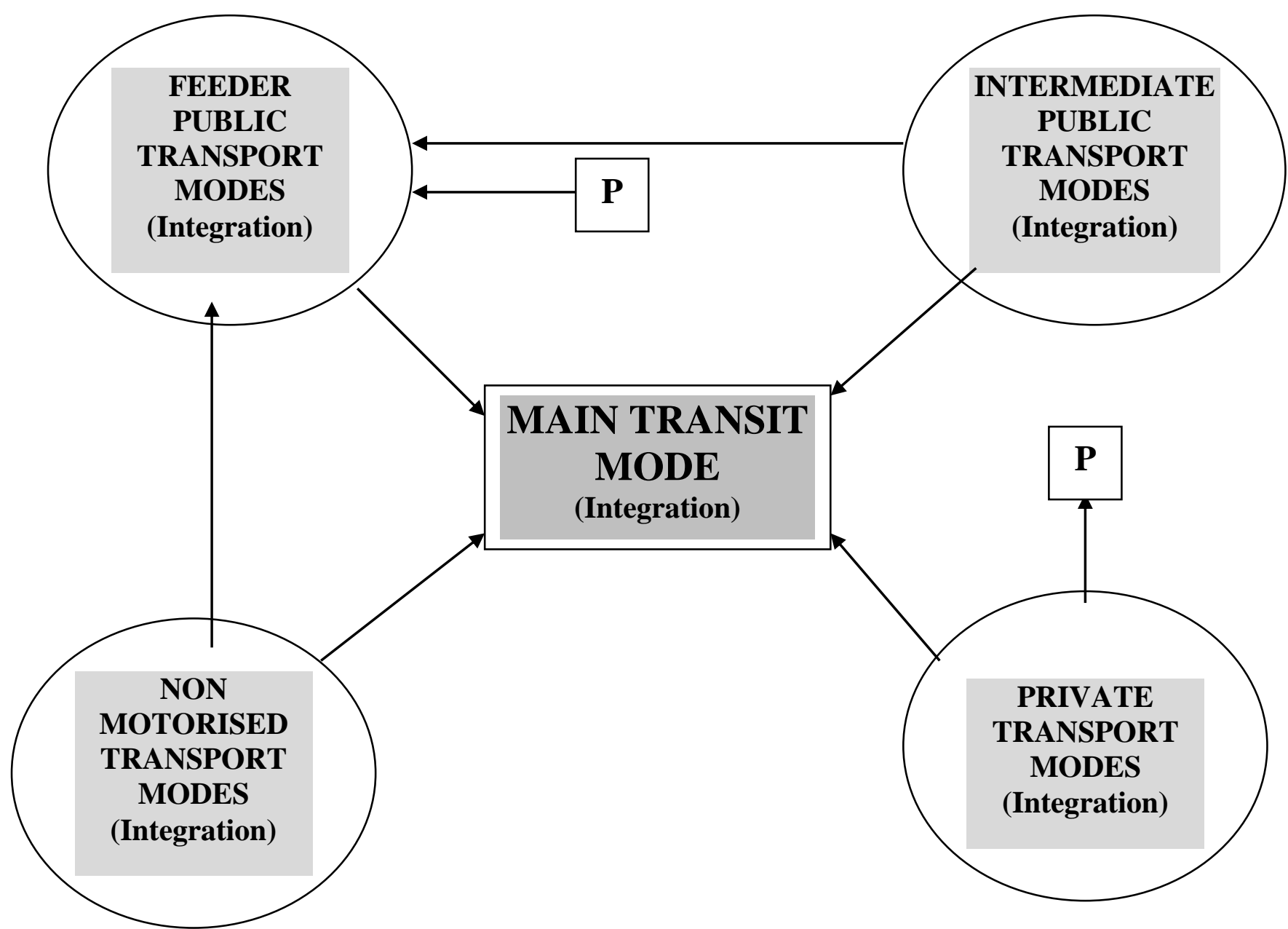


Figure 1 Integrated Mass Transportation System

Table 2Hourly passenger carrying capacities of various public transport systems

\begin{tabular}{|lc|}
\hline System & Hourly Passengers Carrying Capacity \\
\hline LRT & $20,000-25,000$ \\
\hline Suburban Railway & $35,000-45,000$ \\
\hline Under ground railway & $65,000-75,000$ \\
\hline
\end{tabular}

Thus depending on the demand and topography of area, appropriate main transit facility/facilities can be selected. In metropolitan cities where longer travel distances exist usage of suburban trains as a main transit facility is inevitable.

In the integrated system, all trips involve more than one mode and hence passengers are subjected to a transfer. Fundamentally a transfer is perceived as an impediment to travel and is one of the most negative aspects of any trip. When difficulty in transferring is reduced, user satisfaction and patronage both have increased (Lewis, 1986). Since in an integrated public transit system, transfers can not be entirely eliminated; it will be essential to make them as quick and convenient as possible. The efficiency of different modes of transport and main transit facility can be enhanced by over all System Integration. Figure 2 (developed from Roberta, 1979) indicates a typical approach for system integration of the two modes i.e. main transit and feeder service.

\section{$3 \quad$ System integration}

The main objective of System Integration is, bringing together various transport modes and routes to achieve a balance, acceptable to the parties concerned, between the best possible service to the community and acceptable financial consequences. System integration occurs at three levels: institutional, operational and physical (Roberta, 1979). Institutional integration refers to the creation of an organisational framework within which joint planning and operation of transit services can be carried out. Operational integration involves the application of management techniques to optimise 
the allocation of transit resources and co-ordinate services. Physical integration refers to the provision of jointly used facilities and equipment.

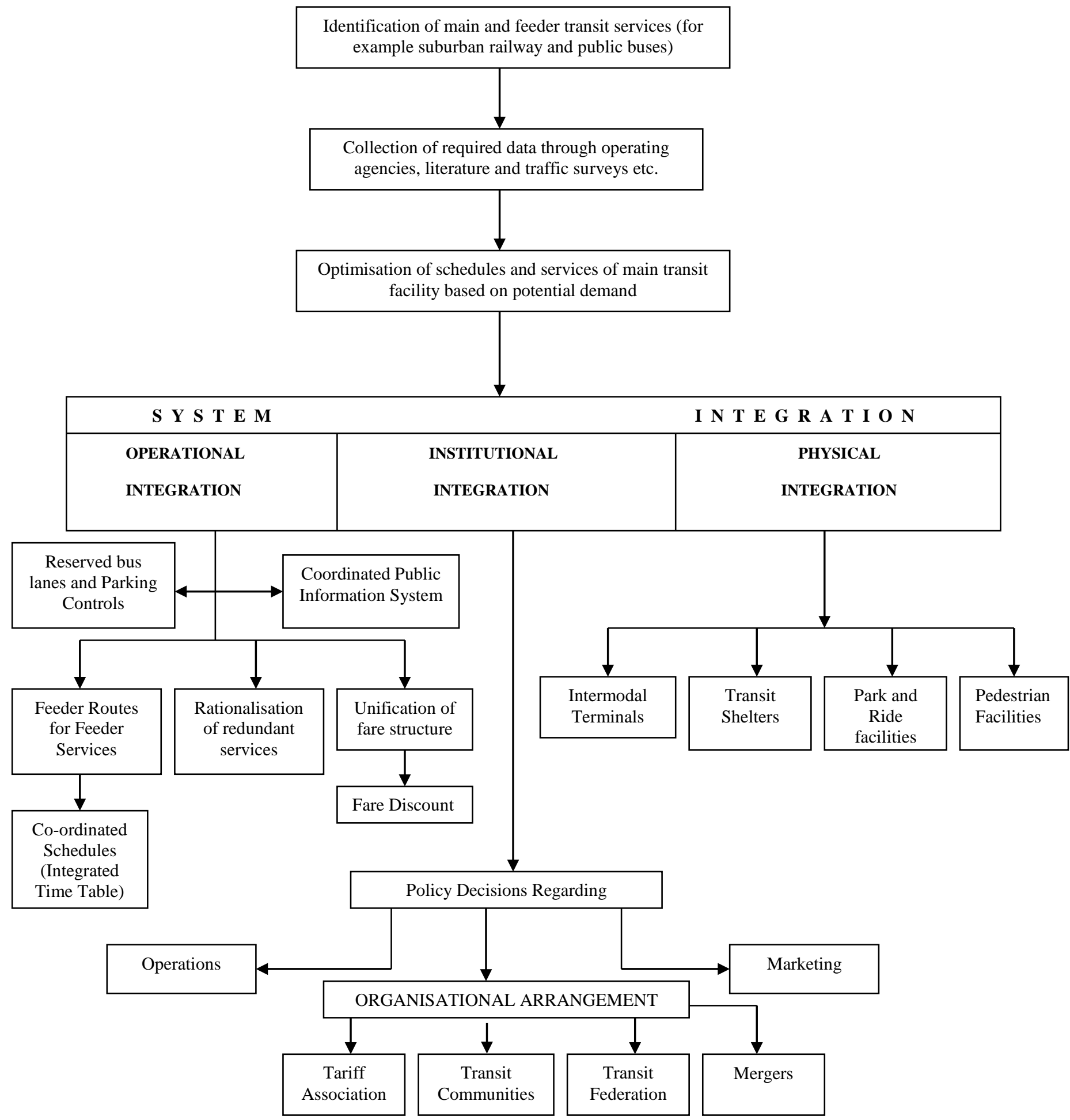

Figure 2 Approach for Integration of Feeder Service and Main Transit Mode 


\subsection{Institutional Integration}

Institutional coordination is vital since without it there can be no lasting integration. The integrating body, be it the organising authority, main operator or a third-party organisation, must have the means to ensure the transport system's oneness and continuity in partnership with all participating bodies. These bodies could help, develop and support the coordination of the whole transport system. However it is important to state that in the metropolitan areas of Europe there is not a single administrative agency in charge of the global management of all transport aspects for traffic and public transport (infrastructure, public transport planning and management, tariff and taxes definition etc). Four types of organisational arrangements for implementing institutional integration are normally considered. These arrangements are Tariff association, Transit communities, Transit federation and Mergers. Table 3 indicates various functions of different organisational arrangements. Among the several organisational alternatives, mergers appear to be the most effective in achieving a high degree of integration. In cases where a merger is difficult, a federation would be the next best institutional arrangement. It provides a long term commitment to a broad range of cooperative activities that can serve existing needs for transit integration, and it can also serve as an interim arrangement leading to eventual merger of its members. Some sort of institutional agreements must be reached before operational and physical integration can take place.

Table 3 Functions of different organisational arrangements

\begin{tabular}{|l|l|l|}
\hline \multicolumn{1}{|c|}{ S. No. } & \multicolumn{1}{|c|}{$\begin{array}{l}\text { Organisational } \\
\text { Arrangements }\end{array}$} & \multicolumn{1}{|c|}{ Functions } \\
\hline 1 & Tariff Associations & $\begin{array}{l}\text { Are limited to contracts on joint tariffs and the distribution of } \\
\text { jointly collected revenues. Associations are suitable only in } \\
\text { situations where the partners do not compete and share no } \\
\text { territory but rather make end to end connections. }\end{array}$ \\
\hline 2 & $\begin{array}{l}\text { Transit } \\
\text { communities }\end{array}$ & $\begin{array}{l}\text { Not only bind them to a common tariff but coordinate routes and } \\
\text { schedules and, if appropriate, pool or exchange some rolling } \\
\text { stock. }\end{array}$ \\
\hline 3 & Transit federations & $\begin{array}{l}\text { Establish a formal federated agency and delegate to it certain } \\
\text { powers related to planning, tariffs, revenue distribution, and so } \\
\text { on. }\end{array}$ \\
\hline
\end{tabular}




\begin{tabular}{|l|l|l|}
\hline 4 & Mergers & $\begin{array}{l}\text { Portions of companies or entire companies, are merged into one } \\
\text { firm within which, the companies either operate as subsidiaries or } \\
\text { lose their identity altogether. }\end{array}$ \\
\hline
\end{tabular}

\subsection{Operational Integration}

The techniques of operational integration include, rationalisation of redundant services, matching modes to service requirements, unification of fare structure, fare discounts, co-ordinated public information systems, reserved bus lanes and streets, development of feeder routes, development of coordinated schedules, parking controls etc. Table 4 indicates functions of these techniques. The concept of 'Balanced use of Street Space' is also found to be very effective in many areas (CfIT Research Report, 2001). This concept has been fundamental in promoting both strong growth in walking, cycling and the ability of public transport to compete with private car. The existing street space should be reallocated to public transport, cycling and walking to meet increased demand.

Table 4 Functions of various techniques for operational integration

\begin{tabular}{|l|l|l|l|}
\hline S. No. & \multicolumn{1}{|c|}{ Techniques } & \multicolumn{1}{c|}{ Functions } \\
\hline 1 & $\begin{array}{l}\text { Rationalisation of } \\
\text { redundant services }\end{array}$ & $\begin{array}{l}\text { Wasteful duplication of transit services by competing } \\
\text { systems is eliminated. } \\
\text { Resources are redeployed to reduce headways on existing } \\
\text { routes and extend services into new areas. }\end{array}$ \\
\hline 2 & $\begin{array}{l}\text { Unification of fare } \\
\text { structure }\end{array}$ & $\begin{array}{l}\text { A single area wide fare structure is established under this that } \\
\text { permits riders to purchase one ticket at the beginning of the } \\
\text { trip and transfer freely between all modes. }\end{array}$ \\
\hline 3 & $\begin{array}{l}\text { It encourages the perception of public transport as a network } \\
\text { where making connections is not penalised by additional } \\
\text { ticket costs or queuing. }\end{array}$ \\
\hline 4 & $\begin{array}{l}\text { Fare discount } \\
\text { Coordinated public } \\
\text { information systems }\end{array}$ & $\begin{array}{l}\text { Reduced fares are offered to accomplish subsidised travel for } \\
\text { selected socio economic groups. } \\
\text { Encourage off peak use of transit through discounts for travel } \\
\text { before or after peak periods. }\end{array}$ \\
\hline 5 & $\begin{array}{l}\text { Information on routes, schedules, fares, and transfer points } \\
\text { for all transit modes and services throughout the urban area is } \\
\text { provided by a centralised source. }\end{array}$ \\
\hline 6 & $\begin{array}{l}\text { Potential demand of various destinations from stations on } \\
\text { main transit facility is identified and feeder routes are } \\
\text { developed to these destinations for feeder services. }\end{array}$ \\
\hline Coordinated & $\begin{array}{l}\text { Schedules of feeder services are determined against the given } \\
\text { schedules of main transit facility so as to minimise the } \\
\text { transfer time at the transfer points. }\end{array}$ \\
\hline
\end{tabular}




\subsection{Physical Integration}

Interchanges should impose the lowest impedance to a passenger's journey. Interchange time between arriving and departing modes should be as low as possible (Leake and Read, 1979). Techniques of physical transit integration include intermodal transfer facilities, transit shelters, park- and-ride facilities and pedestrian facilities.

Intermodal transfer facilities are interchanges between transportation subsystems. It is necessary to optimise various functions of Intermodal transfer facilities. Figure 3 shows a schematic representation of typical intermodal transfer facility system. Intermodal transfer facilities are important because they connect the feeder service system with the main line haul system; they promote passenger accessibility and enhance the utility of the total system. Factors that determine optimal size and location of intermodal transfer facilities, including quantitative data requirement and analytical procedures should be established. Intermodal transfer facility promotes community accessibility to transportation network. The efficient Intermodal transfer facility ease the transfer from one mode to another and enhances the usage of the main transit facility which results into reduction in longer journeys by private and intermediate transportation. Functions of various features of Intermodal transfer facility system are presented in Table 5 .

Transit shelter range from simple weather-protection structures on surface transit routes to 'mini terminals' at important stops and transfer points. The facilities should provide automatic ticket vending machines, locator maps, routes and schedules etc. Comfort and safety of pedestrian movement to and from transit is very important to the successful functioning of public transportation systems. Walking is encouraged by grade-separated "skyways" or underground passageways, escalators, and moving sidewalks that protect the pedestrians from direct contact with moving vehicles. Routes, schedules, and vehicle identification facilities should also be appropriately provided. Appropriate Park and ride facilities are provided so that drivers are encouraged to leave their cars and complete their trips on public transit. Thus park and ride facilities play a very important role for integration of cars with other public transport modes. 


\section{THE COMMUNITY}

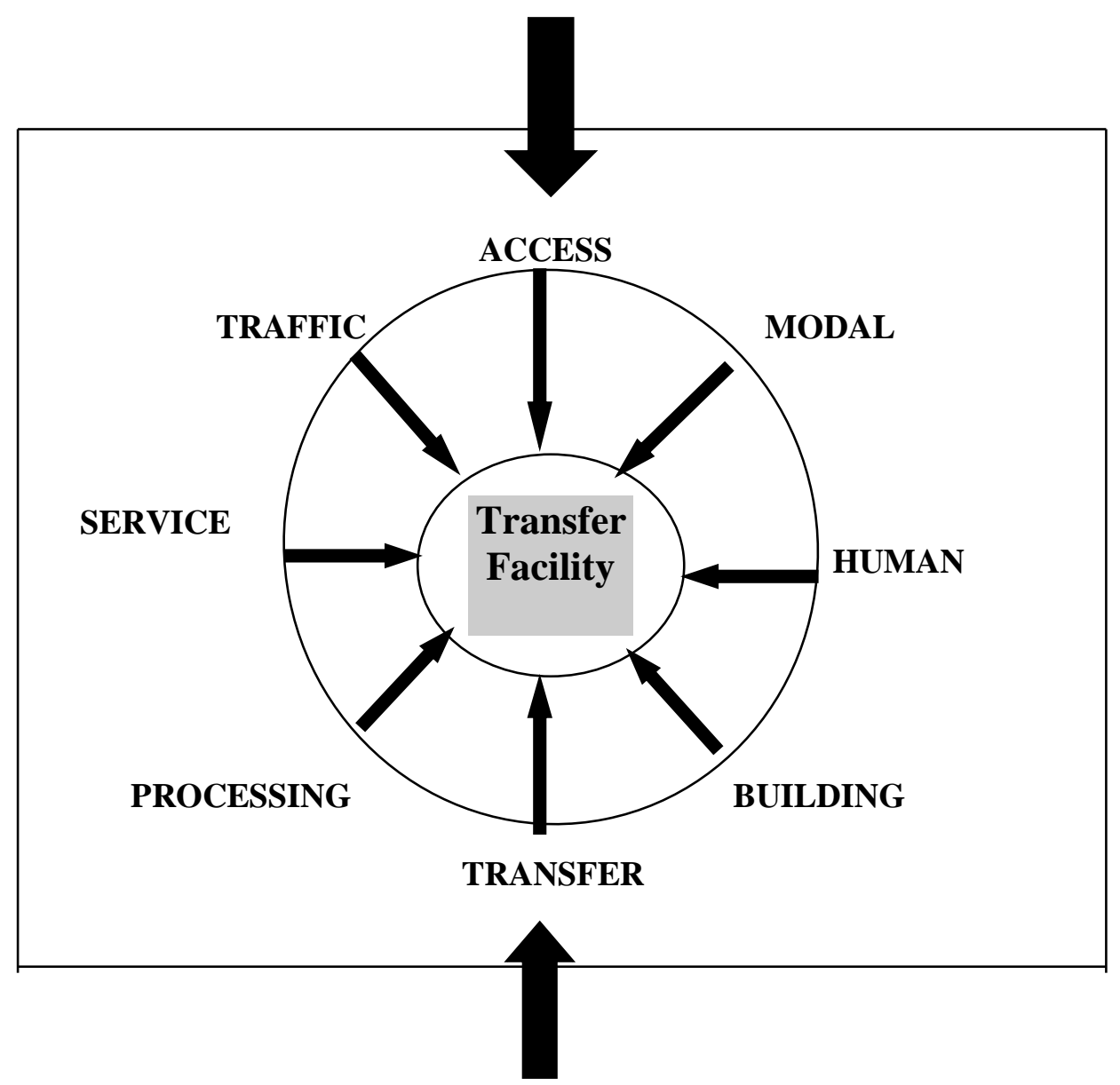

FACILITY DESIGN ELEMENTS

Figure 3 Intermodal Transfer Facility Systems

Source: Specified by committee on Intermodal transfer facilities Transportation Research Board, 1973

\subsection{Integration between car and other modes}

Given that the car will remain the mainstay of our transport system for the foreseeable future. It is essential to integrate the car driver into public transport network. Ease of interchange for car users with bus and rail services is therefore a priority and entry points should be provided throughout the public transport system. These should include more dispersed access points as well as the traditional 
large park and ride sites. A lack of parking spaces inhibits motorists from transferring to the train.

Parking strategies should take into account the proposals to reduce, or even to abolish, charges at

Table 5 Details of various features of intermodal transfer facility

\begin{tabular}{|c|c|c|}
\hline S. No. & Features & Details \\
\hline 1 & Access & $\begin{array}{l}\text { Access adequacy determines the operating capacity of a modal } \\
\text { transfer facility. Inadequate access can result in under use of the } \\
\text { facility and wasted investment. To maximise productivity and } \\
\text { minimise passenger crowding and delay, access facilities must } \\
\text { match passenger demand. }\end{array}$ \\
\hline 2 & Modes & $\begin{array}{l}\text { The physical dimensions, configuration, and operating } \\
\text { characteristics of the modes serving the transfer facility } \\
\text { determine its form. }\end{array}$ \\
\hline 3 & Human & $\begin{array}{l}\text { The relationship of human behavioural factors to facility design } \\
\text { should be established to evaluate alternative designs and their } \\
\text { relationship to increased facility investment and improvements in } \\
\text { service. }\end{array}$ \\
\hline 4 & Building & $\begin{array}{l}\text { The building houses the Intermodal transfer function and include } \\
\text { the electrical and mechanical systems. The basic configuration of } \\
\text { the building is determined by human and modal requirements. } \\
\text { The variability of transportation demand and evolutionary } \\
\text { changes in transportation systems emphasises the need for } \\
\text { flexible building design that is capable of alteration with } \\
\text { characteristics change. }\end{array}$ \\
\hline 5 & Transfer & $\begin{array}{l}\text { Transfer elements are mechanical subsystems requiring } \\
\text { substantial investment and continuing maintenance for movement } \\
\text { and storage of people and goods. When these systems are not } \\
\text { adequate, or are out of service because of mechanical failures, the } \\
\text { passenger may be subjected to delay and inconvenience. }\end{array}$ \\
\hline 6 & Processing & $\begin{array}{l}\text { Processing elements like turnstiles, ticket dispensing devices, and } \\
\text { other passengers control systems also play a very important role } \\
\text { for efficiency of Intermodal transfer facility. Processing system } \\
\text { efficiency can affect passengers' demand. The functions, } \\
\text { capacities, and cost of passengers processing systems should be } \\
\text { established; criteria should be developed to optimise efficiency. }\end{array}$ \\
\hline 7 & Service & $\begin{array}{l}\text { Service elements are auxiliary subsystems such as rest room, } \\
\text { waiting room and concessions. Concessions can be an important } \\
\text { determinant of the economic feasibility of some facilities. There } \\
\text { is a need to determine planning criteria for concessions to } \\
\text { provide guidelines on the amount of revenue for different types } \\
\text { of concessions so that revenue can be optimised. }\end{array}$ \\
\hline 8 & Traffic & $\begin{array}{l}\text { Traffic is related to hourly, daily, seasonal and other factors that } \\
\text { determine the size, efficiency, and service of the facility. Design } \\
\text { guidelines should be established for various types of facilities } \\
\text { based on traffic characteristics and operational techniques. } \\
\text { Procedures should be developed to modify traffic patterns and } \\
\text { provide optimal use of facilities. }\end{array}$ \\
\hline
\end{tabular}


some railway stations (Leake and Read, 1979). A preferential rate for those arriving with passengers in their car is another possibility worthy for further consideration. The existing surface park and ride type interchanges tend to sprawl even more distant from the bus stops or railway station that serves them as demand increases. The underground space can be used as underground interchanges. The underground interchanges can reduce or have no visual impact, no sprawl, facilitate seamless interchange including reduced walking distances, provide pleasant weatherproof and a secure environment.

The integration of private cars with public buses will reduce congestion and other adverse environmental effects especially at urban centres. There are two schemes for integration: 1) Edge of Urban Area Park and Ride (EUAPR) scheme; and 2) Link and Ride strategy. Empirical evidence suggests EUAPR sites intercept motorists only for the final stages of their journey because the sites are very close to the urban areas. Hence their potential contributions to overall car use reduction are limited (WS Atkins, 2001). For the success of park and ride schemes some sort of subsidies are required. Subsidies lead to lowering of the generalised cost of travel and are responsible in part for generation of trips by Park and Ride and the abstraction of trips from public transport. An alternative strategy to park and ride could be 'Link and ride' (LR) based on 'chain' of smaller scale interchanges served by an existing, but enhanced, public transport route. It has been found that a longer range 'link and ride' strategy offers an alternative approach to maintain accessibility of traditional centres whilst at the same time reducing overall car use (Parkhurst, 2000). Further it is established that the interception of car trips at a longer-range can be financially viable.

\subsection{Integration of cycling and public transport}

In order to move towards a sustainable transport system and reduce dependency on the car, a set of good quality options has to be in place. These have to form a framework within which people can have access to their needs and reasonable desires without recourse to private cars. Two of the most important elements of this framework are the pedal cycle and public transport. The pedal cycle is the most environment friendly vehicle but a quality public transport network is also essential. Neither on 
their own can hope to replace trips made by car. The integration of cycling and public transport has the potential to temper the negative side of public transport expansion and assist in consolidation of land use and transport policies aimed at creating environmentally sustainable settlements. The two must work together as a counterpart to traffic restraint and reduction measures. There are four basic areas of integration, which can be defined according to the difficulty by which they can be introduced if not implemented at the outset. These are as follows, in order of difficulty (Wood, 1996): 1) Sharing; 2) Cycle Carriage; 3) Complementary (Cycle parking, hire / loan - a - bike); and 4) Marketing and publicity.

Cycle parking is important for all modes of public transport. Cycle carriage is most relevant to longer distance services, high speed routes or where the terrain is hilly or barrier have to be crossed. The consideration of space sharing is particularly relevant to shorter distances. There are certain schemes like loan - a - bike which can be adopted for short urban journeys. These are clearly useful for people who arrive in city centre by public transport but want the flexibility of bicycle to get around once there. They are in themselves a sort of public transport, complementary to buses, trains and taxies. 'Denmark' has a long tradition of cycling as a mass means of transport. Danish State Railways permits cycle carriage with numbers varying according to the type of train. Following some Dutch experiments, 'Green Bike' schemes appeared in U.K. in early 1990s. There were similar schemes introduced after this scheme at many cities. The major cities promoting such schemes were Cambridge, Exeter, Portsmouth, Lewisham, Copenhagen, Malmo and Zurich. Following planned actions can be adopted for improving bicycle integration with public transport modes. First, cooperation with local authorities is desirable in order to provide easy, safe and secure pedal cycle access to stations. Encourage transport providers to provide cycle-friendly facilities at ports and airports. Second, appropriate programme should be implemented for secure, convenient, covered cycle parking at new and existing main public transport interchanges and park and ride sites. Pedal cycle parking facilities need to be as good as those for cars or preferably better. Third, examine the possibility of improving the cycle carrying capability of trains and long distance buses and coaches. New and refurbished railway passenger rolling stock should have good quality capacious flexible space designed in, able to cope with several cycles. Fourth, provide a fare structure for the transport of 
bicycles aimed at encouraging the integrated use of public transport and bicycles. Cyclist may be willing to accept a charge for cycle carriage if it is low, equitable and user friendly.

\subsection{Walking}

Walking also has a role to play in supplanting car based short trips. Since 1970 walking has declined in all European countries. Luxembourg, Portugal and Netherlands recovered particularly well (all show recovery of over 10 percent). The recovery of UK was among the lowest and in 1995 had the lowest per capita walking distance except for Greece and on a par with Spain and the Irish Republic (Commission for Integrated Transport, 2001). Appropriate facilities for safe walking must be provided like signalised crossing, sheltered foot paths, underpasses, sidewalks, barriers at mid block, grade separated crossing, pedestrian malls, crosswalks, stop lines and better lighting.

\section{4 . Effects on service characteristics and generalised cost due to integration of transport modes}

The factors that affect choice among alternative modes are heterogeneous and numerous. One of the factors which greatly affect choice of the mode is network characteristic (Kadiyali 1997). Network characteristic consists of Travel Time Ratio (TTR), Cost Ratio (CR) and Service Ratio (SR). The ratio of the travel time by public transport and travel time by private car gives a measure of the attractiveness to public transport system. The travel time ratio can be given by following equation.

$$
\begin{aligned}
& \text { TTR }=\frac{X_{1}+X_{2}+X_{3}+X_{4}+X_{5}}{X_{6}+X_{7}+X_{8}} \\
& X_{1}=\text { time spent for walking to public transport vehicle at origin } \\
& X_{2}=\text { time spent for waiting public transport vehicle } \\
& X_{3}=\text { time spent in public transport vehicle (total) } \\
& X_{4}=\text { time spent in transfer from one public transport vehicle to another (for example from } \\
& \quad \text { bus to train or vice versa) } \\
& X_{5}=\text { time spent for walking from public transport vehicle to destination } \\
& X_{6}=\text { time spent in driving the car } \\
& X_{7}=\text { time spent in parking at destination } \\
& X_{8}=
\end{aligned}
$$


It has been found that as travel time ratio increases, the usage of public transport system falls down (Sosslau et al, 1964). Thus in the above equation all the quantities in the numerator can be reduced with the help of effective integration as discussed above and TTR can be reduced which will result into enhanced patronage to integrated public transport system.

The ratio of cost of travel by public transport and cost of travel by car is also one of the important factors influencing mode choice. The relative travel cost is defined as out of pocket travel costs by public transport and private car as follows (Hutchinson, 1974).

$$
\mathrm{CR}=\frac{\mathrm{X}_{9}}{\left(\mathrm{X}_{10}+\mathrm{X}_{11}+\mathrm{X}_{12 / 2}\right) / \mathrm{X}_{13}}
$$

$$
\begin{aligned}
& X_{9}=\text { Public transport fare } \\
& X_{10}=\text { Cost of petrol } / \text { gasoline } \\
& X_{11}=\text { Cost of oil change and lubricant } \\
& X_{12}=\text { Parking cost at destination } \\
& X_{13}=\text { average car occupancy }
\end{aligned}
$$

The factor $X_{9}$ can be controlled by integrated fare structure and thus mode share to public transport can be enhanced (Leake and Read, 1979).

The relative travel service or service ratio is characterised by the ratio of the excess travel times by transit and car. The excess travel time is defined as the amount of time spent outside the vehicle during a trip. The service ratio is defined as follows:

$$
\mathrm{SR}=\frac{X_{1}+X_{2}+X_{4}+X_{5}}{X_{7}+X_{8}}
$$

The values of $X_{1}, X_{2}, X_{4}, X_{5}$ can be controlled by modal integration. Reduced values of these quantities by appropriate facilities and proper coordination will attract more passengers towards integrated public transportation system (Shrivastava and Dhingra, 2000).

The above discussion does not identify 'captive' and 'choice' transit riders. However in the true sense 'choice transit riders' are more concerned towards Generalised cost of the system. Typical generalised cost or disutility of a trip may be estimated from following equation (Hutchinson, 1974). 


$$
\mathrm{Z}_{\mathrm{ij}}{ }^{\mathrm{m}}=\mathrm{a}_{\mathrm{n}} \mathrm{X}_{\mathrm{nij}}{ }^{\mathrm{m}}+\mathrm{b}_{\mathrm{w}} \mathrm{u}_{\mathrm{w}}+\mathrm{c} \quad \begin{aligned}
& \mathrm{n}=1, \ldots \ldots, \mathrm{n} \\
& \mathrm{w}=1, \ldots \ldots \ldots, \mathrm{w}
\end{aligned}
$$

Where,

$$
\begin{aligned}
& Z_{i j}{ }^{m}=\text { the generalised cost of travel between zones ' } i \text { ' and ' } j \text { ' by mode ' } m \text { ' } \\
& x_{n i j}{ }^{m}=\text { the } n^{\text {th }} \text { characteristic of mode ' } m \text { ' between zones ' } i \text { ' and ' } j \text { ' which gives rise to } \\
& \quad \text { the cost of travel by mode ' } m \text { ' } \\
& u_{w}=\text { the } w^{\text {th }} \text { socioeconomic characteristic of a trip maker } \\
& c=\text { constant } \\
& a_{n}, b_{w}=\text { coefficients that reflect the relative contribution that system and tripmaker } \\
& \text { characteristics make to the generalised cost of travel. }
\end{aligned}
$$

Generalised cost of integrated system will certainly be less as compared to system which is not integrated at all. This is due to lesser transfer time between the modes, better access facilities to transit, better transfer facilities etc. Generalised cost formulation for Dublin transportation initiative was derived by Steer Davies Gleave (Gleave, 1994). As per generalised cost waiting and values of time given by him, the value of waiting time / transfer time can be derived as 11.324 cent per minute (for Car available case) and 3.427 cent per minute (for car not available case). Thus overall generalised cost will be reduced for an integrated system due to reduction in waiting time/transfer time between coordinating modes.

A model was developed for integrated public transport system for Dun Laoghaire DART station in Dublin, Ireland (Shrivastava and O'Mahony, 2005). Typical commuters' counts were taken for passengers exiting the DART station during peak hour of 8 to 9 a.m. More than 20 percent commuters were interviewed regarding their destination, mode of transport and travel time. Commuters who did not opt for public buses were enquired about their willingness to shift to public buses if they are coordinated with existing train services. Percentage of commuters likely to shift from other modes of transport to public buses were added with those already using public buses and thus potential demand matrix was obtained for the peak hour. There were 16 designations for which typical total potential demand as observed during peak hour of 8 to 9 a.m. was found to be 778 commuters. Four feeder routes and coordinated schedules for feeder buses were developed against the existing schedules of suburban trains. Due to integrated system about 65.07 percent of demand is satisfied with 
in 0 to 5 minutes of effective waiting and 24.97 percent of demand is satisfied between 6 to 10 minutes of waiting. Thus a total demand of 90.04 percent gets satisfied with in 10 minutes of waiting and entire demand is satisfied before 15 minutes of waiting. Table 6 gives details of transfer time due to proposed integration and the generalised cost, only due to transfer as per the values given by Steer Davies (Gleave, 1994). Total generalised cost due to transfer for peak hour from 8 to 9 am works out to be $€ 430$. It was observed during traffic surveys that in the study area under the present scenario (with out integration) about 60 percent of commuters have to wait on an average of 15 minutes and about 40 percent of commuters have to wait about 25 minutes for getting buses to their destinations during above peak hour. Thus generalised cost of only transfer time for the present scenario for the indicated peak hour works out to be about $€ 1668$. Thus considering only transfer time for commuters during peak hour of 8 to 9 a.m. shows about 74 percent reduction in generalised cost. If other components of generalised cost are also considered then there will be significant reduction due to integration.

TABLE 6 Waiting time details of passengers after integration (8 to 9 a.m.)

\begin{tabular}{|c|c|c|}
\hline $\begin{array}{c}\text { Duration of } \\
\text { Delay in } \\
\text { Minutes }\end{array}$ & $\begin{array}{c}\text { Percentage Demand } \\
\text { Satisfied Overall }\end{array}$ & $\begin{array}{c}\text { Average Generalised cost for all the potential } \\
\text { trip makers } \\
\text { (due to transfer only for car available case) }\end{array}$ \\
\hline $0-5$ & 65.07 & $€ 142$ \\
\hline $6-10$ & 24.97 & $€ 175$ \\
\hline $11-15$ & 09.96 & $€ 113$ \\
\hline More than 15 & Nil & - \\
\hline & & Total: $€ \mathbf{4 3 0}$ \\
\hline
\end{tabular}

It can be shown by Discriminant analysis that probability of selection of integrated transport system increases due to reduction in generalised cost (Z). A typical Figure 4 shows the pattern of frequency distributions based on some arbitrary values of $\mathrm{Z}$ for users of two transport modes i.e. integrated transport system and private car (developed from Hutchinson, 1974). Selection of the modes can be given in the following form in terms of conditional probability. 


$$
\mathrm{P}\left(\frac{I}{Z}\right)=\frac{p 2}{p 1+p 2} \quad \text { also } \quad \mathrm{P}\left(\frac{I I}{Z}\right)=\frac{p 1}{p 1+p 2}
$$

Where I correspond to integrated transport system and II for Private car, $\mathrm{p} 2$ and $\mathrm{p} 1$ are probabilities of selection of integrated transport system and private car respectively against the generalised cost ' $z$ '. It can be concluded from the figure - 4 that probability of selection of integrated transport system increases due to reduction in generalised cost. The same conclusion can be drawn by even Probit and Logit analysis.

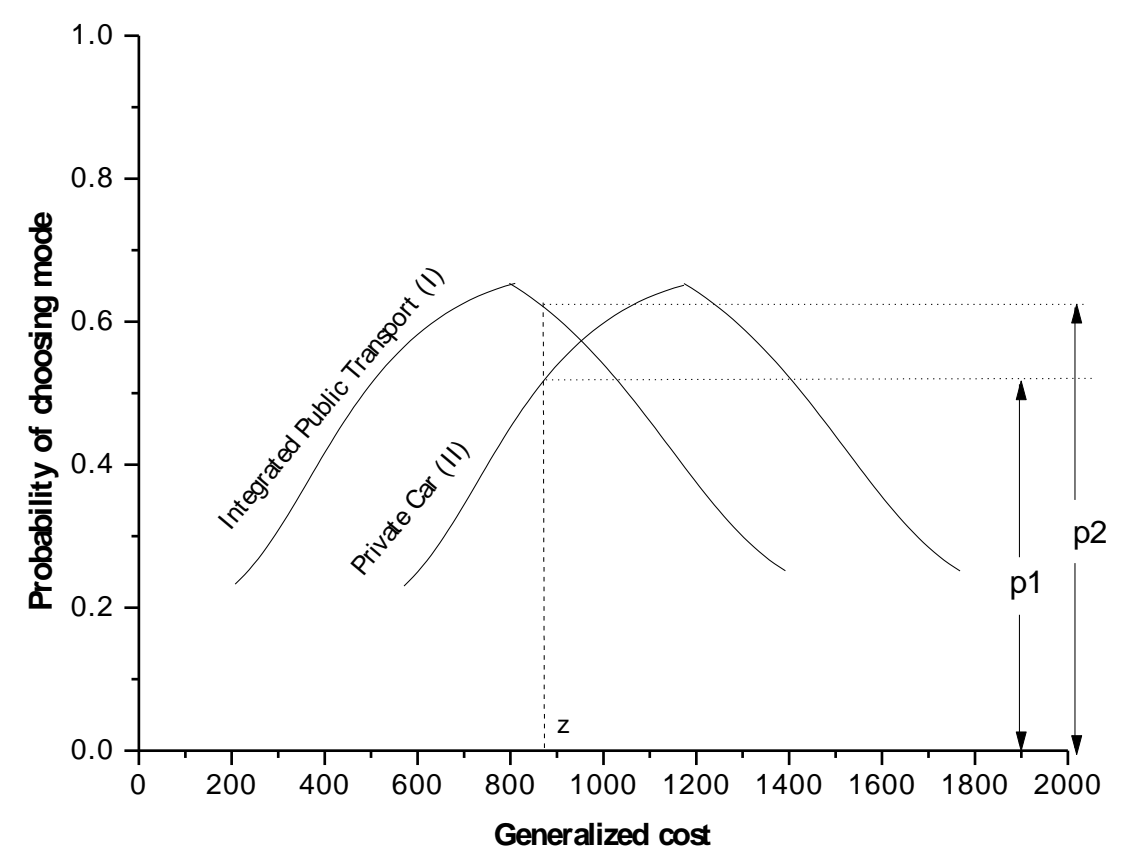

Figure 4: Discriminant analysis for the choice of the mode

Thus, as per the above discussion reduction in transfer is one of the prime aspects for integration. Public mode transfer time in hours can be given by following equation for a rectangular grid network (Massachusetts Institute of Technology, 1966).

Public mode transfer time in hours $=\frac{\operatorname{Pr} n}{3 T v}$

Where,

Capacity of vehicle $-P$, Routes per square $\mathrm{km}-r_{n}$, Average trip length per trip end $-T$ Average velocity in the stream $-v$ 
It can be seen in the above equation that the capacity of vehicle plays a very important role for transfer time. Therefore capacity of vehicle should be decided based on the demand on particular routes. Higher capacity compared to available demand results into lower load factors which may lead to uneconomical operations (Shrivastava and O’Mahony, 2004).

Thus, for integration viability of conventional bus services, non motorised transport, private car etc with main transit facility can be justified in urban and inter urban routes but if trips are more dispersed and involve rural travel then it is found that Demand Responsive Transport is more effective and efficient (Marcus et al, 2004).

\section{Demand responsive transport (DRT)}

Increasingly, conventional bus services do not meet the needs of a large section of the population. This is due to increasing incomes and car ownership levels and the resulting dispersal of activity centres and trip patterns. One possible solution is public transport systems that can operate effectively with lower and more dispersed patterns of demand than the bus, i.e. Demand Responsive Transport (DRT). There can be various categories of DRT services. The first main category provides feeder links to conventional public transport. Typically this would be a DRT service providing an interchange at a rail station or into a bus route. This type of DRT services are known as 'Interchange $D R T^{\prime}$. Except where main transit and DRT services operate at a high frequency, integrated timetabling with connecting services and ideally guaranteed connections are advisable, and it is desirable to encourage flexibility in service design to ensure connections are achieved at both directions, i.e. DRT to main transit and main transit to DRT. The vehicle interior should be of high specification, and ideally as close to a taxi environment as possible. If modal shift from car is desired then fares need to be competitive with perceived motoring costs (including parking costs at stations). The second category called Network $D R T$ enhances public transport either by providing additional services, or by replacing uneconomic services in a particular place or at certain times. Rather than simply being a feeder into conventional public transport, DRT services can be used to provide additional capacity to conventional public transport by serving new markets or to expand an existing market. Destination-specific DRT is closely related to the above category of network DRT. Here, 
DRT modes have been developed to serve particular destinations such as airports or employment locations. Substitute DRT occurs where a DRT system totally (or substantially) replaces conventional public transport services. This represents a reinvention of public transport. With long-term changes towards more dispersed settlements, well suited to travel by car, that have travel demands fragmented physically and in time, there may be locations where total replacement of buses by DRT could well be appropriate.

\section{Problems to be faced for effective integration}

Some of the major problems for achieving successful integrated system are as follows: First, Difference in organisational structure and political control of participant bodies pose problems for integration. Changes of policy and political control lead to resultant difficulty of long term planning (Taylor, 1977). Second, to bring together the various organisations with differing objectives, responsibilities and constraints, is in itself an integration matter of some considerable complexity. Third, there are cross boundary problems to be solved for successful integration. Local authorities are, quite naturally, concerned about the facilities with in their own boundaries but most of them are not concerned with the well being of neighbouring counties. Fourth, public participation plays a very important role in any changes to public transport and indeed to any land use proposals that affect the provision of public transport. Delay or not proper public participation leads to frustration to operators and hence operator is ignorant of healthy constructive criticism of scheme. Fifth, the government consultative document on transport policy, future services and long distance operations should be reviewed. If this is not done then entire exercise of integration may go in vain due to any change in transport policy. Sixth, rigidity in fixing the time tables once for all dates may not be proper (Taylor, 1977). There should always be room for change at short notice in response to recent changes in circumstances. Seventh, punctuality is of prime importance to all public transport operators, but when integration has taken place it becomes vital. Timetables must be realistic in their running allowances, giving adequate but not extravagant, room for late running. Eight, for specially designed connecting services such as bus/rail commuter services, it is essential to have a through booking facility so that a passenger is not obliged to book twice and suffer the penalty of two high rate fares. Regular liaison 
between operators should be carried out to co-ordinate fares increases, both in size and timing. This is difficult, especially where political considerations are more important than commercial. Ninth, operators should integrate their publicity material. The complete service over a shared route, or the services in a certain area, will attract business better than individual advertisement of parts of the service. Tenth, the impact that the county councils can have upon integration is usually in direct proportion to their financial involvement. The financial implications are always first to be considered when proposals are investigated. The balancing out of the financial effect upon all public undertakings of integration schemes should be recognised. Eleventh, effective consultation and communication at all levels is the key to the staff's acceptance and cooperation in any integration scheme. Staff, trade unions etc should be convinced that moves towards integration are to the ultimate benefit of the industry.

\section{$7 \quad$ Conclusions}

In Britain, Tyne and Wear area has shown drastic improvement towards mobility due to integration of its various transport modes (Lewis, 1986). Modal integration has improved mobility and brought sustainable development at Barcelona in Spain (world city), Munich in Germany (metropolitan area), Stuttgart in Germany (medium city), Graz in Austria (Small city) and Achterhoek in Netherlands (Rural area) (CfIT Research Report, 2001).

The following points can be concluded from above discussion towards integration among various transport modes for sustainable development.

- First, due to heavy growth of traffic especially private and intermediate public transport services in the metropolitan cities of developed and developing countries traffic congestion, delays, environmental pollution and accidents are prevailing. It is urgently required to develop an echo friendly integrated public transport system in which various participating modes complement each other rather than competing. 
- Second, for development of an integrated system it is required to identify appropriate main transit facility for an urban area based on demand and topography of the area. Other modes should serve as feeder with emphasis on public buses and non-motorised modes.

- Third, required facilities for promotion of non-motorised modes viz. bicycles and walk should be developed. If required facilities priority wise of these green modes are provided then they can be effectively coordinated with main transit facility.

- Fourth, major thrust should be given to overall system integration i.e. effort should be made for Operational, Institutional and Physical Integration of public transport systems like suburban railway and public buses. The task for system integration will be easier if different operating agencies work under one umbrella.

- Fifth, it is seen that by adopting integrated transport system Travel Time Ratio, Travel Cost Ratio and Service Ratio decreases which in turn would encourage commuters to shift from other modes of transport to integrated public transport system and thus increases patronage towards it.

- Sixth, it is also found that integrated public transport system is more efficient in reducing generalized cost of transportation. It can be ascertained by Discriminant analysis, Logit and Probit analysis that reduction in generalised cost increases the probability of its usage.

- Seventh, the capacity of public transport mode at the transfer points should be appropriately selected as per the demand on various routes so as to reduce generalised cost of transfer.

- Eighth, intermodal transfer facilities play a very important role for system integration. Its efficient design leads to better integration among different modes. It is required to identify facilities design elements for commuters and different co-ordinating modes at transfer facility and while designing transfer facilities each element should be given due weightage. These intermodal transfer facilities should be developed at transfer points to/from main transit facility and at feeder public transport facility after identifying potential trips which will be attracted to each transfer point by different modes.

- Ninth, if the effort is to be made to integrate existing system then it is required to identify the probable future potential demand to each mode. This is because due to integration there will be 
changes in travel pattern and choice of modes by commuters and some of them may shift to public transport and non-motorised modes from private and intermediate public transport. This potential demand to different modes should be considered for analysis of integrated system and design of various facilities.

- Tenth, an integrated strategy for transportation modes is very important for developing countries like India where the share of public transport is very high. Especially the metropolitan cities like Bombay (Mumbai), Delhi, Madras (Chennai) and Calcutta have public transport share more than 70 percent. It has been observed that in spite of having such a large share of public transport there is no coordination among public transport modes (Shrivastava and Dhingra, 2002) on the contrary there is fierce competition among public transport modes which leads to commuter dissatisfaction (Shrivastava, 1991). An efficient integrated system is essential for such cities of developing countries for economic growth.

- Eleventh, public transport could be expected to play a more cost effective role if an integrated approach is applied throughout Ireland (New Ireland Forum, 1984).

For cities like Dublin in Ireland it is essential to study the effect on trip pattern due to the new tram system (LUAS) along with existing and future land use development. Also overall impact of quality bus corridors should be studied on trip pattern (Dublin Transport Office, 2001). Adequate park and ride facilities should be provided at DART/LUAS stations and other potential locations. Integrated fare and ticketing strategy, quality interchange facilities and passengers' information system should be further strengthened.

\section{References}

CfIT Research Report, 2001, http://www.cfit.gov.uk/research/ebp/stage2/ accessed on 06.08.2004

Commission for Integrated Transport, (2001). Research Report on European best practice in delivering integrated transport, Key Findings. http://www.cfit.gov.uk/research/ebp/key/03.htm accessed on 05.08.2004

Dublin Transport Office (2001), "A Platform for Change - Summary Report”, Summary of Integrated Transportation Strategy for Greater Dublin Area, 2000 - 2016. 
European Commission (1999), "INTRAMUROS: integrated urban transport concepts and systems", European Commission, Directorate General Transport, Luxembourg: Office for official publications of the European commission.

Gleave Steer Davies (1994). Dublin Transportation Initiative, Final Report and Technical reports (Ten), Stationery Office, Dublin.

Government of India (1987), "Estimation of Total road Transport Freight and Passenger Movement in India for the year 2000 AD”, Department of Surface Transport, Government of India, New Delhi.

Hickey T.R.(1992), "Co-ordination of Intermodal Transfers at LRT Stations", Transportation Research Record 1361,pp.136-140

Hutchinson B.G., (1974), "Principles of Urban Transport Systems Planning”, Published by McGrawHill Book Company, Washington D.C., 54 - 80 .

Kadiyali L.R. (1997), "Traffic engineering and Transport planning”, sixth edition, Khanna publisher, New Delhi, India, 709 - 716.

Leake G R and Read M (1979), "The potential of feeder bus systems serving commuter rail stations", Traffic Engineering and Control, Vol. 20, No. 2, pp. 52-58.

Lewis Harold (1986), The impact of Metro and Public Transport Integration in Tyne and Wear, Metro Monitoring and Development Study, Transport and Road Research Laboratory, University of Newcastle upon Tyne, UK

Marcus Enoch, Stephen Potter, Graham Parkhurst Mark Smith, (2004) "INTERMODE: Innovations in Demand Responsive Transport", Department for Transport and Greater Manchester Passenger Transport Executive, Final Report

Massachusetts Institute of Technology (1966), Project Metran: an integrated, evolutionary transportation system for urban areas. MIT press, 238-245.

Mezghami Mohamed (2003), "From Public Transport to Integrated Mobility”, Public Transport International. 
http://www.uitp.com/Events/madrid/mediaroom/Backgrounders/transport_quality.htm accessed on $\underline{05.08 .2004}$

New Ireland Forum (1984), "Integrated policy and planning for transport in a New Ireland" Dublin: Stationary Office, 1984, New Ireland Forum sectoral studies.

Parkhurst Graham (2000), 'A Longer - Range Strategy for Car - Bus Interchange: The 'Link-AndRide' concept' In 'Traffic Engineering and Control', pp 319 - 324

Patankar P.G. (1999), "Public Transport in Mumbai - Are we not kidding city Commuters" Newsletter, Indian Roads \& Transport Development Association, Vol. LXVIII, No.9, pp.1-7.

Roberta Remak (1979), “System Integration” in Public Transportation Planning, Operations and Management authored by Gray G.E. and Hoel L.A., published by prentice hall Inc. pp. $205-222$.

Shrivastava Prabhat (1991), “Utility of Suburban Railway for Madras City: A Case Study from Beach - Tambaram section”, Thesis on Master of Technology submitted at Transportation System Engineering Division, Civil Engineering Department, Indian Institute of Technology, Madras, Chennai, India,

Shrivastava Prabhat and Dhingra S.L. (2000), "Development of a Model for Operational Integration of Public Transport Mode - A Case study of Mumbai”. Proceedings of All India Seminar on Urban Mass Transit Systems held during 15-16, by Institution of Engineers, Maharashtra State centre, India, pp. 52- 61.

Shrivastava Prabhat and Dhingra S.L. (2001), "Urban mass transportation systems", proceedings of National seminar on National connectivity vision: surface transportation \& communication organized by Indian National Academy of Engineering on January 19-20, 2001, pp.119 - 134

Shrivastava Prabhat and Dhingra S.L. (2002), "Development of co-coordinated schedules using Genetic Algorithms" ASCE journal of Transportation Engineering, USA, Vol. 128,No. 1, pp. 8996. 
Shrivastava Prabhat and O’Mahony Margaret (2005), "Modeling an Integrated Public Transport System - A Case Study in Dublin Ireland” Submitted to 'Transportation' Journal.

Sosslau A.B., Heanue K.E. and Black A.J. (1964), “Evaluation of new modal split procedure”, Public Roads, vol. 33, No.1, Washington.

Taylor D (1977), "Problems of integration and how they can be overcome", Proceedings of Symposium on 'Integrating Public Transport', organised by Department of Civil Engineering, Division of Transport Engineering, University of Newcastle Upon Tyne, 29-31.

W S Atkins (1998), The Travel effect of Park and Ride. W S Atkins Planning Consultants, Epsom for Department of Environment Transport and Regions (Authors: C. Harris, B Cooper \& Whitfield)

WS Atkins Transport Planning Group (2001), “European Best Practice in the Delivery of Integrated Transport", Report on Stage 2: Case Studies.

White Peter R (2002), "Public Transport: Its planning, management and operation", $4^{\text {th }}$ edition, Spon, London.

Wood Chris (1996), “Integrating Cycling and Public Transport”, TransPlan Occasional Paper No. 1, TransPlan, Transport and Planning Research Network, Norwich, UK, 3-28 